Collection: IUFRO 7.01.00, Ithéus (Brazil, 2013) \& Beijing (China, 2014)

"Forest Response to Climate Change and Air Pollution"

Guest Editors: Paoletti E, Kozovitz A, Feng Z, Bytnerowicz A

\section{Advantages of the point-intercept method for assessing functional diversity in semi- arid areas}

\author{
Alice Nunes ${ }^{(1-2)}$, Susana Tápia ${ }^{(1)}$, Pedro Pinho ${ }^{(1-3)}$, Otília Correia ${ }^{(1)}$, \\ Cristina Branquinho ${ }^{(1)}$
}

Semi-arid areas are particularly susceptible to the loss of biodiversity as a consequence of global change. Species functional traits are key drivers of functioning and resilience of ecosystems, thus monitoring of functional trait diversity is urgently needed. The assessment of functional diversity requires the quantification of species and/or their traits in the field, though there is no consensus on the best plant-sampling method to be used. The aim of this study was to compare the performance of the point-intercept (PT) method with two area-based approaches, the modified-Whittaker (MW) and Dengler (DE) methods, to assess functional diversity in semi-arid areas. The herbaceous community of a savanna-like Mediterranean woodland was surveyed at the two extremes of a regional precipitation gradient (dry to wet). Efficiency in the quantification of species/ traits, precision of cover estimates, and their effect on functional diversity metrics computed for eight functional traits were compared. Results showed that the examined methods differed in their efficiency in quantifying species/traits in both sites. With the DE method, fewer species were detected than with the MW and PT methods, which yielded similar values. The PT method had a higher precision in the quantification of both dominant and non-dominant species/traits. It also had a higher community evenness, mainly in the wet location, which allowed the analysis of a greater number of species/traits within the $\mathbf{8 0 \%}$ "dominance" threshold (i.e., species representing $80 \%$ of the relative cover of community), a critical aspect of functional diversity assessments. In addition, the PT method yielded higher estimates for multi-trait functional evenness, as well as different estimates (either higher or lower than $\mathrm{MW}$ and $\mathrm{DE}$ ) of single-trait community weighted means (for $\mathrm{N}$-fixing ability and flowering onset), functional dispersion (for $\mathrm{N}$-fixing ability and specific leaf area), and functional evenness (for height and flowering onset). In spite of the observed differences among methods in the assessment of functional diversity, the PT approach demonstrated important advantages in the non-destructive, fine-scale monitoring of semi-arid areas, where "less dominant" species may play a critical role.

Keywords: Dengler Method, Drylands, Field Plant Sampling, Functional Structure, Functional Diversity, Grassland, Modified-Whittaker, Point-intercept Method

\section{Introduction \\ Semi-arid ecosystems are characterized by water scarcity and often by low soil produc- tivity. Due to global change, they are highly vulnerable to losses of biodiversity, which underpins many critical ecosystem services (Reynolds et al. 2007). The more dramatic effects on these ecosystems are often pre- ceded by subtle changes in relative species' abundance and/or in the dominance of spe- cific functional traits (Chapin et al. 2000, Scheffer et al. 2001). Even in less abundant functional groups (e.g., nitrogen-fixers), the}

(1) Centro de Biologia Ambiental, Faculdade de Ciências, Universidade de Lisboa, Campo Grande, C2, Piso 5, 1749-016 Lisboa (Portugal); (2) Departamento de Biologia e CESAM-Centre for Environmental and Marine Studies, Universidade de Aveiro, Campus Universitário de Santiago, 3810-193 Aveiro (Portugal); (3) CERENA- Centro de Recursos Naturais e Ambiente, Universidade de Lisboa, Instituto Superior Técnico, Av. Rovisco Pais, 1049-001 Lisboa (Portugal)

\section{(a) Cristina Branquinho (cmbranquinho@fc.ul.pt)}

Received: Feb 02, 2014 - Accepted: Jul 16, 2014

Citation: Nunes A, Tápia S, Pinho P, Correia 0 , Branquinho C, 2014. Advantages of the point-intercept method for assessing functional diversity in semi-arid areas. iForest 8: 471-479 [online 2014-10-31] URL: http://www.sisef.it/iforest/contents/? id=ifor $1261-007$

\section{Communicated by: Elena Paoletti}

identity and divergence, which often respond more rapidly to environmental constraints than richness, and may have a strong impact on ecosystem processes (Chapin et al. 2000, Mouillot et al. 2011, Maestre et al. 2012b). Functional diversity, defined as the value, range, and relative abundance of the functional traits of biological communities in a given ecosystem, was shown to be a better and more universal predictor of ecosystem vulnerability than species diversity, which does not reflect the uneven role played by species in the maintenance of ecosystem processes (Tilman et al. 1997, Díaz et al. 2007). Functional diversity is usually assessed by the use of several metrics (e.g., communityweighted mean and functional richness, evenness, and divergence). Recent investigations have demonstrated the better predictive ability of indexes that consider species abundances rather than richness alone (Schleuter et al. 2010, Mouillot et al. 2011). However, there is no consensus on the best field method for functional diversity assessment. Biomass (Prieur-Richard et al. 2002), frequency (De Bello et al. 2005), and most commonly cover (Frenette-Dussault et al. 2012, Lavorel et al. 2008) are ordinarily used in the estimation of functional diversity. Nonetheless, cover estimates obtained by different methods may vary considerably (Abrahamson et al. 2011) and may therefore affect estimates of functional diversity.

The desirable characteristics of a coversampling method to monitor functional diversity are primarily efficiency, precision, and reproducibility. Efficiency expresses the 
amount of information collected in relation to the resources devoted to achieve that information. Precision, i.e., the bias between two measurements of the same object by the same observer, is essential to detect changes in the dominance of traits and to ensure measurement repeatability. The reproducibility of a method to be used by different observers largely depends on its objectivity, which is assumed to be higher for methods less vulnerable to the observer bias. The methods most commonly used for sampling plant cover are the area-based, modified-Whittaker's method (MW), and the point-intercept method (PT), based on transects (Goodall 1953, Stohlgren et al. 1995, Elzinga et al 2001). The PT method was originally proposed for grasslands (Goodall 1953), and is based on the interception of species at predefined points along a transect. It is thus less biased than area-based methods, which rely on the visual assessment of plant cover (Elzinga et al. 2001). The line-intercept method is mainly used in patchy shrublands (De las Heras et al. 2011), but it is not suitable for species (e.g., grasses, some forbs, shrubs) with narrow or lacy canopies, whose extension is hard to delineate when plant density is high (Elzinga et al. 2001). Dengler's plo (DE - Dengler 2009) is an additional areabased, MW-derived method recently proposed, but without the MW shortcomings of non-uniform plot sizes or shapes, nestedness, and spatial arrangement of smaller subplots Although considerable attention has been devoted to comparisons of plant-sampling approaches over the last 20 years (Floyd \& Anderson 1987), few studies have assessed the performance of different cover-sampling methodologies with respect to functional diversity (Abrahamson et al. 2011). For instance, the use of different methods may lead to a different number of species included in the $80 \%$ "dominance" threshold - thus affecting the "amount of trait diversity" analyzed - as proposed by Garnier et al. (2004) and Pakeman \& Quested (2007) based on the mass-ratio hypothesis (Grime 1998).

With the aim of determining the best cover-sampling method for non-destructive

Tab. 1 - Main characteristics of the sites sampled in this study. Sources: Atlas Digital do Ambiente (2011), Nicolau (2002).

\begin{tabular}{|c|c|c|}
\hline & Dry & Wet \\
\hline Characteristics & $\begin{array}{c}\text { Almodôvar, } \\
\text { Beja }\end{array}$ & $\begin{array}{c}\text { Montemor-o-Novo } \\
\text { Évora }\end{array}$ \\
\hline Geographical coordinates & $\begin{array}{c}37^{\circ} 36^{\prime} 11.04^{\prime \prime} \mathrm{N} \\
8^{\circ} 0^{\prime} 40.86^{\prime \prime} \mathrm{W}\end{array}$ & $\begin{array}{c}38^{\circ} 29^{\prime} 42.00^{\prime \prime} \mathrm{N} \\
8^{\circ} 12^{\prime} 58.31^{\prime \prime} \mathrm{W}\end{array}$ \\
\hline $\begin{array}{l}\text { Annual average precipitation } \\
1961-1990(\mathrm{~mm})\end{array}$ & 592 & 748 \\
\hline $\begin{array}{l}\text { Precipitation coefficient } \\
\text { of variation }(\%)\end{array}$ & 63 & 59 \\
\hline $\begin{array}{l}\text { Annual average temperature } \\
1931-1960\left({ }^{\circ} \mathrm{C}\right)\end{array}$ & 17.5 & 16.0 \\
\hline Altitude (m) & 253 & 187 \\
\hline
\end{tabular}

fine-scale monitoring of functional diversity in semi-arid areas, we compared the abovementioned PT, MW, and DE methods in a vegetation survey carried out in Mediterranean Holm oak (Quercus ilex L.) woodland. Specifically, wet and dry locations were selected along a regional precipitation gradient to determine potential differences in methods' performance in relation to water scarcity. In the study area water deficit, often combined with low soil productivity, is the major limiting factor for plant establishment, thus lowering vegetation density and/or diversity. The following questions were addressed: (i) Are there differences in the efficiency of these methods in quantifying the relative abundances of species and traits? (ii) Does the efficiency of these methods vary depending on the amount of precipitation and, consequently, with changing vegetation density and/or diversity? (iii) Do the differences lead to different estimates of functional diversity metrics? The above methods were compared in terms of time-efficiency and precision of cover estimates for individual species, and main genera and families as well. Also, we assessed the effect of their use on several functional structure and diversity metrics, namely, "community-weighted mean" and functional richness, evenness, and divergence (Garnier et al. 2004, Villéger et al. 2008, Laliberte \& Legendre 2010). We hypothesized the PT method (less biased and more reproducible) would provide more precise cover estimates than the other abovementioned methods, allowing a better quantification of functional diversity over time by different observers and across different environmental conditions.

\section{Material and methods}

\section{Study sites}

The study was performed in a Mediterranean Holm oak (Quercus ilex L.) woodland (montado) in southwestern Portugal. This semi-natural savanna-like ecosystem has been shaped by human use since long time. Dominant soils in the study area are poor and shallow lithosols, grazing is mode- 
cumulatively attaining a relative cover $\geq$ $80 \%$, as well as for genera cumulatively attaining a relative cover $\geq 50 \%$ and for the main botanical families, namely, Asteraceae, Fabaceae, and Poaceae (cumulatively attaining a relative cover $\geq 90 \%$ )

\section{Functional traits}

To compare functional structure and diversity estimates among methods, we selected eight traits reflecting the strategies used by species to cope with the main environmental constraints, i.e., water and soil-nutrient limitations. Binary, semi-quantitative, and quantitative traits were considered, including growth form, $\mathrm{N}$-fixing ability, dispersal mode, life cycle, flowering onset and duration, vegetative height at maturity, and specific leaf area (leaf area/dry weight - Tab. 3). These traits are related to stress and disturbance avoidance/tolerance, resource acquisition and retention, and reproductive and dispersal abilities (Cornelissen et al. 2003). Traits were assigned to each species (Tab. S1 in Appendix 1) based on either direct observations or literature reports (Franco 1971, Castro 2008, Porto et al. 2011, Bernard-Verdier et al. 2012). Growth form (graminoid or other) and dispersal mode (anemochorous or other) were coded as binary traits to reflect the most relevant characteristics in the grassy plant community (Tab. 3).

\section{Functional diversity metrics}

To describe functional diversity, we used the indexes proposed by Villéger et al. (2008), who considered species within a community distributed in a multidimensional functional space. This approach has the advantage of taking into account species abundance and considering simultaneously several traits. Using these indexes, functional richness, functional evenness, and functional divergence were computed for the combined eight traits listed in Tab. 3. A detailed description of the computational method is reported by Villéger et al. (2008). Functional richness is the amount or range of functional multidimensional space occupied by a community and is calculated based on the convex-hull volume method. Functional evenness reflects the regularity of the distribution of abundance in a trait space. A higher functional evenness is expected to correspond to a fuller occupation of a niche space by coexisting species (Mason et al. 2005). Functional divergence quantifies the functional dissimilarity of trait values within a community. For instance, divergence is high when the functional trait values of the most abundant species are far outside the center of the functional trait range (Villéger et al. 2008). High functional divergence can be used as an indicator of a high degree of niche differentiation and low competition for resources (Mason et al. 2005). Additionally, the func-

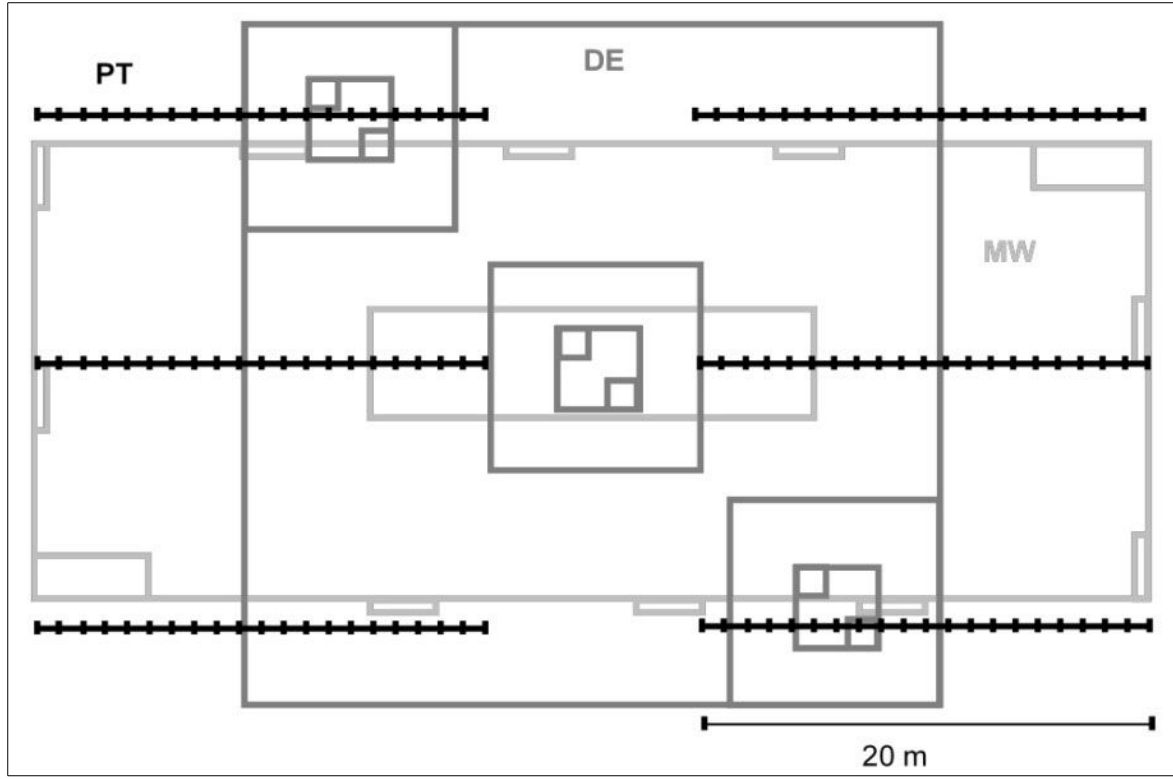

Fig. 1 - Sampling design and field overlaying schemes. (MW): modified Whittaker's plots (light gray); (DE): Dengler's plot (dark gray); (PT): point-intercept method (black).

Tab. 2 - Description of the sampling design adopted for each of the three survey methods analyzed.

\begin{tabular}{|c|c|c|c|}
\hline Feature & $\begin{array}{l}\text { Modified-Whittaker } \\
\text { (MW) }\end{array}$ & $\begin{array}{l}\text { Dengler } \\
\text { (DE) }\end{array}$ & $\begin{array}{l}\text { Point-intercept } \\
\text { (PT) }\end{array}$ \\
\hline ption & $\begin{array}{l}20 \times 50 \mathrm{~m} \text { plot with } \\
\text { one } 100-\mathrm{m}^{2}, \text { two } 10- \\
\mathrm{m}^{2} \text {, and ten } 1-\mathrm{m}^{2} \text { sub- } \\
\text { plots }\end{array}$ & $\begin{array}{l}31.6 \times 31.6 \mathrm{~m} \text { plot with } \\
\text { three } 100 \mathrm{~m}^{2}, \text { three } 10 \\
\mathrm{~m}^{2} \text {, and six } 1 \mathrm{~m}^{2} \\
\text { subplots }\end{array}$ & $\begin{array}{l}\text { six } 20 \mathrm{~m} \text { transects with } \\
41 \text { points each spaced } \\
\text { every } 0.5 \mathrm{~m}\end{array}$ \\
\hline $\begin{array}{l}\text { Measurement } \\
\text { method }\end{array}$ & $\begin{array}{l}\text { Species presence in a } \\
1000-\mathrm{m}^{2} \text { plot; cover } \\
\text { estimates in ten } 1-\mathrm{m}^{2} \\
\text { subplots }\end{array}$ & $\begin{array}{l}\text { Species presence in a } \\
1000-\mathrm{m}^{2} \text { plot; cover } \\
\text { estimates in six } 1-\mathrm{m}^{2} \\
\text { subplots }\end{array}$ & $\begin{array}{l}\text { Cover and species } \\
\text { presence measured by } \\
\text { point interceptions }\end{array}$ \\
\hline Area/ Cover & $10 \times 1 \mathrm{~m}^{2}$ & $6 \times 1 \mathrm{~m}^{2}$ & $6 \times 41=246$ points \\
\hline length Presence & $1000 \mathrm{~m}^{2}$ & $1000 \mathrm{~m}^{2}$ & $6 \times 41=246$ points \\
\hline
\end{tabular}

Tab. 3 - Description of the functional traits considered in the study. For species trait assignments, see Tab. S1 (Appendix 1). Source: (1) direct observation/measurement; (2) Franco (1971); (3) Porto et al. (2011); (3) Castro (2008); (4) Bernard-Verdier et al. (2012).

\begin{tabular}{|c|c|c|c|c|}
\hline Type & $\begin{array}{l}\text { Functional } \\
\text { trait }\end{array}$ & $\begin{array}{l}\text { Categories/ } \\
\text { Units }\end{array}$ & Function & Source \\
\hline \multirow[t]{5}{*}{ Binary } & \multirow[t]{2}{*}{ Growth form } & Graminoid & \multirow{2}{*}{$\begin{array}{l}\text { Disturbance avoidance and } \\
\text { tolerance, decomposition rate }\end{array}$} & \multirow[t]{2}{*}{1,2} \\
\hline & & No & & \\
\hline & \multirow[t]{2}{*}{$\mathrm{N}$-fixing ability } & Yes & \multirow{2}{*}{$\begin{array}{l}\text { Resource acquisition, } \\
\text { nutrient cycling }\end{array}$} & \multirow[t]{2}{*}{1} \\
\hline & & No & & \\
\hline & Dispersal & $\begin{array}{l}\text { Anemochory } \\
\text { Other }\end{array}$ & Dispersal distance & 1,3 \\
\hline \multirow{5}{*}{$\begin{array}{l}\text { Semi- } \\
\text { quantitative }\end{array}$} & \multirow[t]{3}{*}{ Life cycle } & Annual & \multirow{3}{*}{$\begin{array}{l}\text { Stress and disturbance avoidance } \\
\text { and tolerance }\end{array}$} & $1,2,3$ \\
\hline & & Biennial & & - \\
\hline & & Perennial & & - \\
\hline & Onset flowering & Initial month & \multirow{2}{*}{$\begin{array}{l}\text { Reproductive strategy, } \\
\text { stress avoidance }\end{array}$} & 2 \\
\hline & $\begin{array}{l}\text { Flowering } \\
\text { duration }\end{array}$ & $\begin{array}{l}\text { Number of } \\
\text { months }\end{array}$ & & 2 \\
\hline \multirow[t]{2}{*}{ Quantitative } & Height & $\mathrm{cm}$ & $\begin{array}{l}\text { Light capture, competitive vigor, } \\
\text { dispersal distance }\end{array}$ & 1 \\
\hline & Specific leaf area & $\mathrm{mm}^{2} \mathrm{mg}^{-1}$ & $\begin{array}{l}\text { Photosynthetic rate, growth rate, } \\
\text { leaf life span }\end{array}$ & 3,4 \\
\hline
\end{tabular}


tional dispersion (Laliberte \& Legendre 2010), which is closely related to Rao's quadratic entropy, was calculated for all the traits combined. Functional dispersion is defined as the weighted mean distance in multidimensional trait space of individual species from the weighted centroid of all species, using as weight the species' relative abundance.

We also calculated the functional dispersion and functional evenness for each trait individually, as well as the "communityweighted mean" (CWM), proposed by Garnier et al. (2004), for the three methods at each location. CWM is defined as the average trait value in a community weighted by the relative abundances of the species carrying each value, and reflects the dominan traits in a community. All calculations were carried out using the "dbFD" function implemented in the FD package (Laliberte \& Shipley 2011) and running under the $\mathrm{R}^{\circ}$ environment (R Core Team 2013).

\section{Statistical analysis}

Separate tests were performed for each location, since site comparison was out of the scopes of this analysis (see above). Departure from normal distribution of data was tested by Kolmogorov-Smirnov tests. Kruskall-Wallis nonparametric tests were applied to test for differences among methods in individual species cover, cover of the main genera and families, and functional structure and diversity estimates. Multiple comparisons were carried out by pairwise Wilcoxon rank sum tests using Bonferroni's adjustments at $\alpha=0.05$. To remove variation due to mean effect size (Lewontin 1966), Levene's test for homogeneity of variances was applied on log-transformed species' cover values to detect significant differences in the precision of estimates. To compare the precision of cover estimates among methods, the coefficient of variation $(\mathrm{CV}$ : ratio of standard deviation to mean) was analyzed with likelihood ratio tests (Verrill \& Johnson 2007), thereby removing variation due to differences between mean cover values. Student's $t$-test was used to compare species diversity indexes. Nonparametric and Levene's tests were conducted using $\mathrm{R}^{\mathscr{\odot}}$ version 3.0.2 (R Core Team 2013).

\section{Results}

The average time needed for two people to complete the vegetation survey at dry and wet locations was 125 and $170 \mathrm{~min}$, respectively, ranging from 93 to $207 \mathrm{~min}$, with no considerable differences among the MW, DE, and PT methods (data not shown).

The overall richness recorded with the MW method was higher than that determined using the DE method within $1000-\mathrm{m}^{2}$ plots. By contrast, in $1-\mathrm{m}^{2}$ plots or $20-\mathrm{m}$ transects similar cumulative richness were obtained by the MW and PT methods, whereas fewer species were detected using the DE method (Tab. 4). At the wet location, the PT method revealed a higher diversity index and a higher evenness than either MW or DE methods (Tab. 4).

At the species level, whenever differences were noted, the PT method generally yielded absolute cover estimates that were significantly higher than those obtained with the other two methods at both locations (Tab. 5). The PT method also revealed a lower CV both for more and for less abundant species at the wet location (e.g., Vulpia myurus, Chamaemelum mixtum, Cerastium glomeratum) and for less abundant species at the dry location (Lolium rigidum) The number of species necessary to attain a relative cover of $80 \%$ (relative to the sum of all species cover) differed among the three methods, with consistently higher values using the PT method. At the dry location, the $80 \%$ threshold was reached with 8,7 and 3 species using the PT, MW and DE methods, respectively. At the wet location, these differences were even higher: 17, 10, and 7 species for the PT, DE, and MW methods, respectively (Tab. 5).

Whenever there were differences in the cover of the main genera and botanical families, significantly higher estimates and lower CVs were obtained with the PT method than with the other methods, particularly at the dry location (Tab. 6). Cover estimates for Poaceae species were highest using the PT method, at both locations. At the dry location, the PT method yielded cover values for Asteraceae family species and for the genus Vulpia higher than those obtained with the DE and MW methods, respectively, while at the wet location estimates for Fabaceae species with PT were higher than with MW (Tab. 6). The precision of the cover estimates was significantly higher for estimates obtained with PT (lower CV) than with MW for the genera Agrostis and Vulpia at the dry location, and for Asteraceae species at both locations (Tab. 6).

Of the functional metrics performed for the combined eight traits, only functional evenness differed significantly among the methods used, with higher estimates for the PT method (Fig. 2).

Functional metrics computed individually for the four binary, semi-quantitative, and quantitative traits are shown in Fig. 3. The results for the other four traits are provided in Fig. S1 (Appendix 1). The DE method resulted in lower CWM values for $\mathrm{N}$-fixing ability at both locations and in higher estimates of functional dispersion than those provided by either PT or MW at the dry location (Fig. 3). The CWM of flowering onset was lower using PT than DE at both locations, whereas functional evenness estimates with DE were higher than those obtained with either other methods at the wet location. Height functional evenness was higher with PT than with DE at the wet location, whereas the functional dispersion of specific leaf area differed with each of the three methods at both dry $(\mathrm{DE}>\mathrm{PT})$ and wet (DE $>\mathrm{MW}$ ) locations (Fig. 3).

\section{Discussion}

In this study, three methods commonly used in the field to quantify species/traits showed remarkable differences of efficiency, leading to divergent estimates of the "community-weighted" functional diversity metrics, regardless of the trait values themselves. This "field sampling-method effect" on functional diversity estimates has relevance in plant functional ecology, especially when the aim of the study implies a finescale survey. Indeed, a number of studies relied on plant abundance measured in the field to weight trait importance in the computation of functional metrics, while collecting at least some of the species trait values from bibliographic sources or databases (Fischer et al. 2013, Gerhold et al. 2013). Our results showed that the field method chosen 
Tab. 5 - Absolute mean cover (\%) and coefficient of variation (CV) recorded for the most common species (attaining $\geq 80 \%$ relative cover) by each method (MW: modified-Whittaker; DE: Dengler; PT: point-intercept) at dry and wet locations. Values with different letters are significantly different across columns after Bonferroni's test adjusted $\mathrm{P}<0.017(\mathrm{~N} \geq 6)$. Lowercase letters refer to cover comparison and uppercase letters to CV comparison. Poaceae species: Agrostis pourretii, Chaetopogon fasciculatus, Gaudinia fragilis, Holcus annuus, Vulpia myuros,Lolium rigidum, Bromus lanceolatus; Asteraceae species: Chamaemelum mixtum, Carlina racemosa, Crepis vesicaria, Tolpis barbata, Leontodon taraxacoides; Fabaceae species: Ornithopus compressus, Trifolium campestre, Trifolium cernuum, Trifolium glomeratum, Trifolium striatum; Caryophyllaceae species: Cerastium glomeratum. (§): Species cumulatively attaining $\geq 80 \%$ of relative cover with each method are indicated.

\begin{tabular}{|c|c|c|c|c|c|c|c|c|c|c|c|c|c|}
\hline \multirow{3}{*}{ Family } & \multirow{3}{*}{ 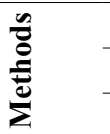 } & \multicolumn{6}{|c|}{ Dry } & \multicolumn{6}{|c|}{ Wet } \\
\hline & & \multicolumn{2}{|c|}{ MW } & \multicolumn{2}{|c|}{ DE } & \multicolumn{2}{|c|}{ PT } & \multicolumn{2}{|c|}{ MW } & \multicolumn{2}{|c|}{ DE } & \multicolumn{2}{|c|}{ PT } \\
\hline & & Mean & $\mathrm{CV}$ & Mean & $\mathrm{CV}$ & Mean & $\mathrm{CV}$ & Mean & $\mathrm{CV}$ & Mean & $\mathrm{CV}$ & Mean & $\mathrm{CV}$ \\
\hline \multirow{7}{*}{ Poaceae } & Apour & $67.0^{\S}$ & 0.2 & $80.0^{\S}$ & 0.2 & $76.4^{\S}$ & 0.1 & $45.0^{\S}$ & 0.6 & $16.7^{\S}$ & 0.8 & $30.9^{\S}$ & 0.6 \\
\hline & Cfasc & $7.5^{\S}$ & 3.4 & 1.6 & 0.9 & $8.9^{\S}$ & 1.5 & 0.1 & 5.8 & - & - & $4.5^{\S}$ & 2.2 \\
\hline & Gfrag & $6.8^{\mathrm{a} s}$ & 0.6 & $5.7^{\mathrm{a}}$ & 0.4 & $32.5^{\text {b§ }}$ & 0.4 & $5.0^{\S}$ & $1.2^{\mathrm{AB}}$ & $8.8^{\S}$ & $1.2^{\mathrm{A}}$ & $18.3^{\S}$ & $0.3^{\mathrm{B}}$ \\
\hline & Hannu & $14.8^{\S}$ & 1.0 & 8.9 & 0.2 & $24.4 \S$ & 0.5 & $3.7^{\S}$ & $4.4^{\mathrm{A}}$ & 1.7 & $0.0^{\mathrm{B}}$ & $2.0^{\S}$ & $0.9^{\mathrm{AB}}$ \\
\hline & Vmyur & $9.0^{\mathrm{a} \S}$ & 1.3 & $28.3^{\mathrm{ab} \S}$ & 0.5 & $46.3^{\mathrm{b} \S}$ & 0.2 & 2.4 & $1.5^{\mathrm{A}}$ & $6.8^{\S}$ & $2.0^{\mathrm{AB}}$ & $10.6^{\S}$ & $1.0^{\mathrm{B}}$ \\
\hline & Lrigi & 0.2 & $1.7^{\mathrm{A}}$ & 0.1 & $0.0^{\mathrm{B}}$ & 2.0 & $0.9^{\mathrm{B}}$ & 1.6 & 2.3 & 1.3 & 1.3 & $18.3^{\S}$ & 1.0 \\
\hline & Blanc & 0.2 & 1.3 & 0.1 & 0.0 & 2.8 & 1.4 & 0.4 & 1.1 & 1.2 & 3.3 & $0.4^{\S}$ & 2.4 \\
\hline \multirow[t]{5}{*}{ Asteraceae } & Cmixt & 0.2 & 0.9 & 0.8 & 0.8 & $3.7^{\S}$ & 0.9 & $13.7^{\S}$ & $1.4^{\mathrm{AB}}$ & $12.0^{\S}$ & $1.5^{\mathrm{A}}$ & $8.5^{\S}$ & $0.5^{\mathrm{B}}$ \\
\hline & Crace & $17.6^{\S}$ & 0.7 & $15.8^{\S}$ & 0.5 & $26.8^{\S}$ & 0.2 & - & - & - & - & - & - \\
\hline & Cvesi & $4.9^{\mathrm{a} \S}$ & 3.2 & $1.2^{\mathrm{ab}}$ & 1.3 & $8.9^{\mathrm{b} \S}$ & 0.5 & $5.2^{\mathrm{a} \S}$ & 0.7 & $11.8^{\mathrm{ab} \S}$ & 0.7 & $22.8^{\mathrm{b} \S}$ & 0.5 \\
\hline & Tbarb & - & - & 0.2 & 0.0 & 0.4 & 2.4 & $11.0^{\S}$ & 0.8 & $18.8 \S$ & 0.4 & $17.9^{\S}$ & 0.6 \\
\hline & Ltara & - & - & - & - & 0.4 & 2.4 & $0.2^{\mathrm{a}}$ & $6.4^{\mathrm{A}}$ & $1.9^{\mathrm{ab} \S}$ & $0.9^{\mathrm{AB}}$ & $2.8^{\mathrm{b} \S}$ & $0.4^{\mathrm{B}}$ \\
\hline \multirow[t]{5}{*}{ Fabaceae } & Ocomp & 0.9 & 4.8 & 0.8 & 2.5 & 3.7 & 0.9 & 1.9 & 0.8 & $4.5^{\S}$ & 0.8 & $5.3^{\S}$ & 1.0 \\
\hline & Tcamp & 1.7 & 2.4 & 0.6 & 0.7 & 2.4 & 1.5 & 1.1 & 2.1 & 1.2 & 1.8 & $1.2^{\S}$ & 1.7 \\
\hline & Tcern & - & - & - & - & - & - & 2.1 & 5.3 & 0.1 & - & $6.5^{\S}$ & 1.5 \\
\hline & Tglom & - & - & - & - & - & - & $5.9^{\S}$ & 1.6 & $7.0^{\S}$ & 1.1 & $5.3^{\S}$ & 0.8 \\
\hline & Tstri & - & - & - & - & - & - & 2.7 & 1.2 & $2.8^{\S}$ & 0.8 & $4.9^{\S}$ & 1.2 \\
\hline Caryophyl. & Cglom & - & - & - & - & - & - & 0.4 & $5.4^{\mathrm{A}}$ & 0.2 & $1.2^{\mathrm{A}}$ & $2.0^{\S}$ & $0.9^{\mathrm{B}}$ \\
\hline
\end{tabular}

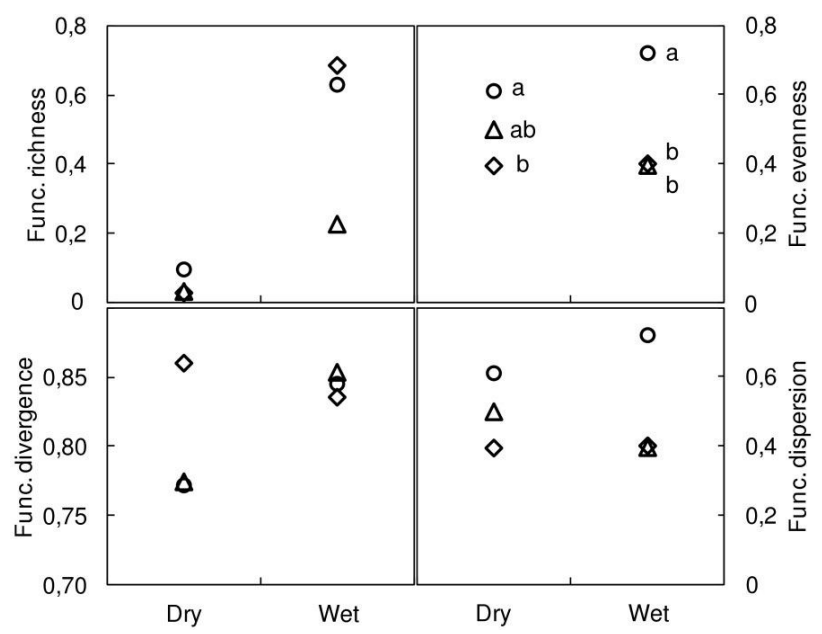

Fig. 2 - Overall functional diversity indices ( 8 traits) at dry and wet locations. Functional richness, functional evenness, functional divergence (Villéger et al. 2008), and functional dispersion (Laliberte \& Legendre 2010). Methods: modified-Whittaker (MW, diamonds); Dengler (DE, triangles); point-intercept (PT, circles). Different letters indicate significant differences between methods after Bonferroni's test adjusted $\mathrm{P}<0.017(\mathrm{~N} \geq 6)$.

Tab. 6 - Absolute mean cover (\%) and coefficient of variation (CV) recorded for the main genera (attaining >50\% relative cover) and fami lies (attaining $>90 \%$ relative cover) for each method (MW: modified-Whittaker; DE: Dengler; PT: point-intercept) at dry and wet locations. Values with different letters are significantly different across columns after Bonferroni's test adjusted at $\mathrm{P}<0.017$ ( $\mathrm{N} \geq 6$ ). Lowercase letters refer to cover comparison and uppercase letters to CV comparison.

\begin{tabular}{|c|c|c|c|c|c|c|c|c|c|c|c|c|c|}
\hline \multirow{3}{*}{ Taxa } & \multirow{3}{*}{ Genera } & \multicolumn{6}{|c|}{ Dry } & \multicolumn{6}{|c|}{ Wet } \\
\hline & & \multicolumn{2}{|c|}{ MW } & \multicolumn{2}{|c|}{ DE } & \multicolumn{2}{|c|}{ PT } & \multicolumn{2}{|c|}{ MW } & \multicolumn{2}{|c|}{ DE } & \multicolumn{2}{|c|}{ PT } \\
\hline & & Mean & $\mathrm{CV}$ & Mean & $\mathrm{CV}$ & Mean & $\mathrm{CV}$ & Mean & $\mathrm{CV}$ & Mean & $\mathrm{CV}$ & Mean & $\mathrm{CV}$ \\
\hline Main & Agrostis & 67.0 & $0.4^{\mathrm{A}}$ & 80.0 & $0.2^{\mathrm{B}}$ & 76.4 & $0.1^{\mathrm{B}}$ & 45.0 & 0.7 & 16.7 & 1.6 & 30.9 & 0.6 \\
\hline \multirow{4}{*}{ genus } & Chamaem. & 0.3 & 1.0 & 0.8 & 1.0 & 3.7 & 0.9 & 13.7 & 1.4 & 12.0 & 1.5 & 8.5 & 0.5 \\
\hline & Tolpis & 0.0 & - & 0.2 & 2.5 & 0.4 & 2.5 & 11.0 & 0.9 & 18.8 & 0.4 & 17.9 & 0.6 \\
\hline & Trifolium & 1.8 & 1.8 & 0.6 & 0.8 & 2.8 & 1.4 & 15.0 & 0.7 & 12.9 & 0.9 & 25.2 & 0.6 \\
\hline & Vulpia & $9.0^{\mathrm{a}}$ & $1.2^{\mathrm{A}}$ & $28.3^{\mathrm{ab}}$ & $0.5^{\mathrm{AB}}$ & $46.3^{\mathrm{b}}$ & $0.2^{\mathrm{B}}$ & 2.4 & 1.4 & 6.8 & 2.0 & 10.6 & 1.0 \\
\hline \multirow{3}{*}{$\begin{array}{l}\text { Main } \\
\text { families }\end{array}$} & Asteraceae & $39.3^{\mathrm{ab}}$ & $0.6^{\mathrm{A}}$ & $19.4^{\mathrm{a}}$ & $0.3^{\mathrm{AB}}$ & $53.7^{\mathrm{b}}$ & $0.2^{\mathrm{B}}$ & 30.7 & $0.6^{\mathrm{A}}$ & 44.6 & $0.4^{\mathrm{AB}}$ & 54.9 & $0.3^{\mathrm{B}}$ \\
\hline & Fabaceae & 32 & 11 & 19 & 10 & 81 & 0.8 & $17.1^{\mathrm{a}}$ & 0.6 & $18.7^{\mathrm{ab}}$ & 0.7 & $35.0^{\mathrm{b}}$ & 0.4 \\
\hline & Poaceae & $107.3^{\mathrm{a}}$ & 0.2 & $125.7^{\mathrm{ab}}$ & 0.2 & $207.7^{\mathrm{b}}$ & 0.1 & $59.0^{\mathrm{ab}}$ & 0.4 & $37.2^{\mathrm{a}}$ & 0.4 & $90.7^{\mathrm{b}}$ & 0.3 \\
\hline
\end{tabular}


CWM

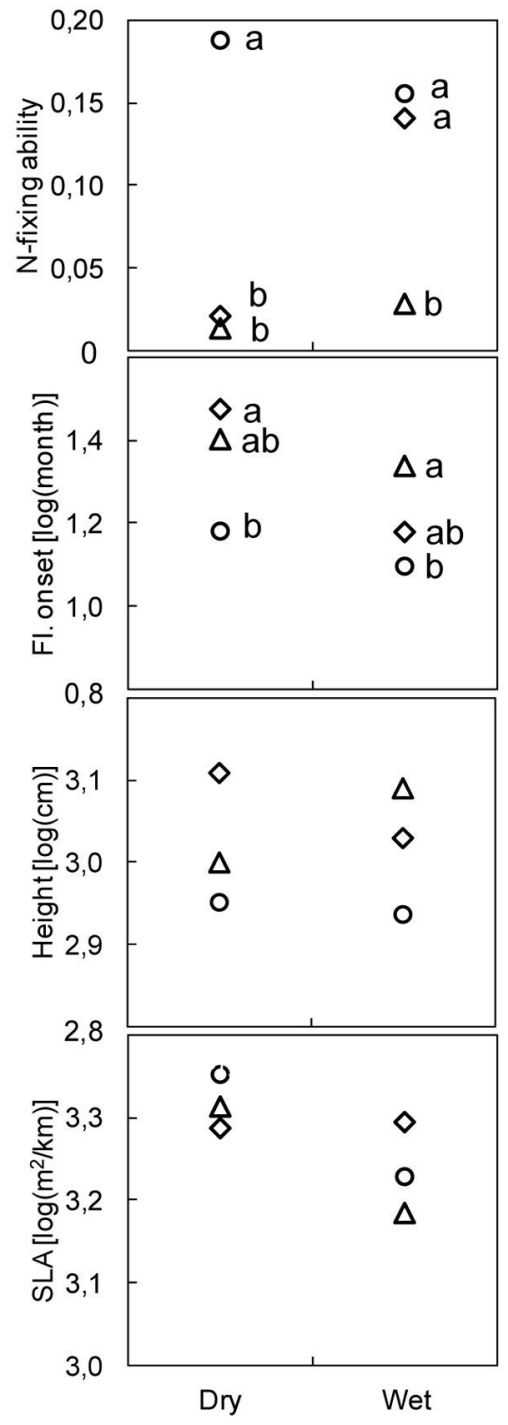

Func. dipersion

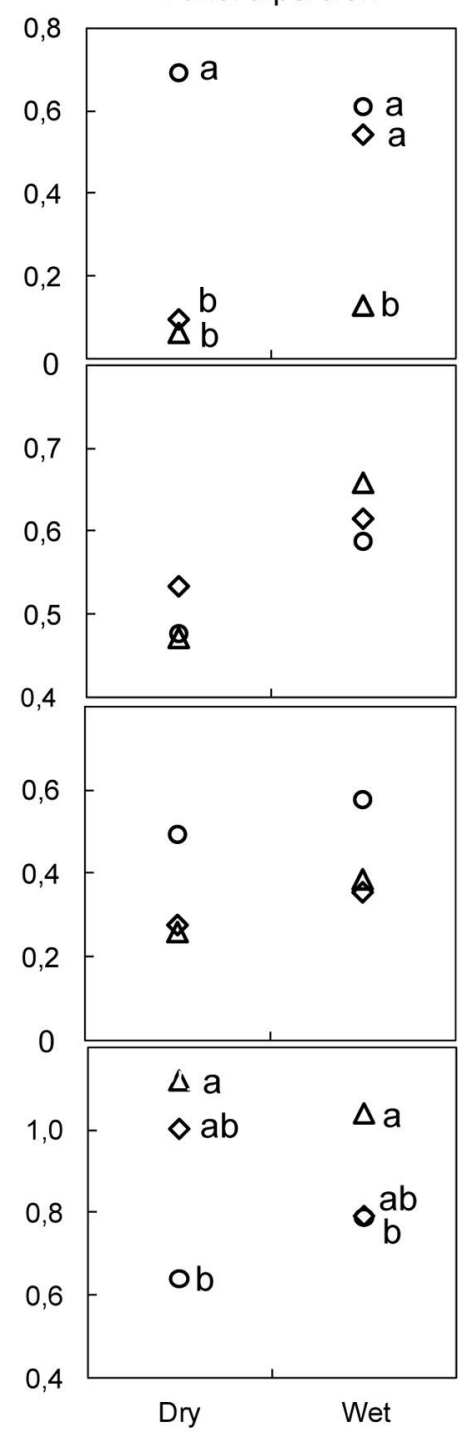

Func. evenness

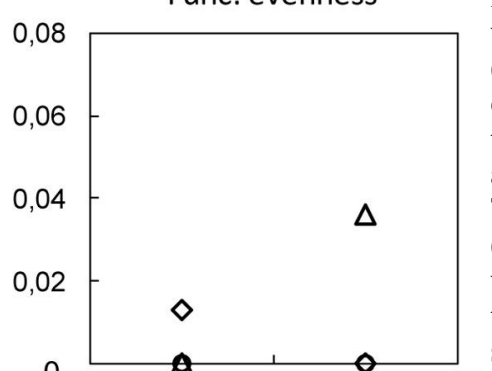

0
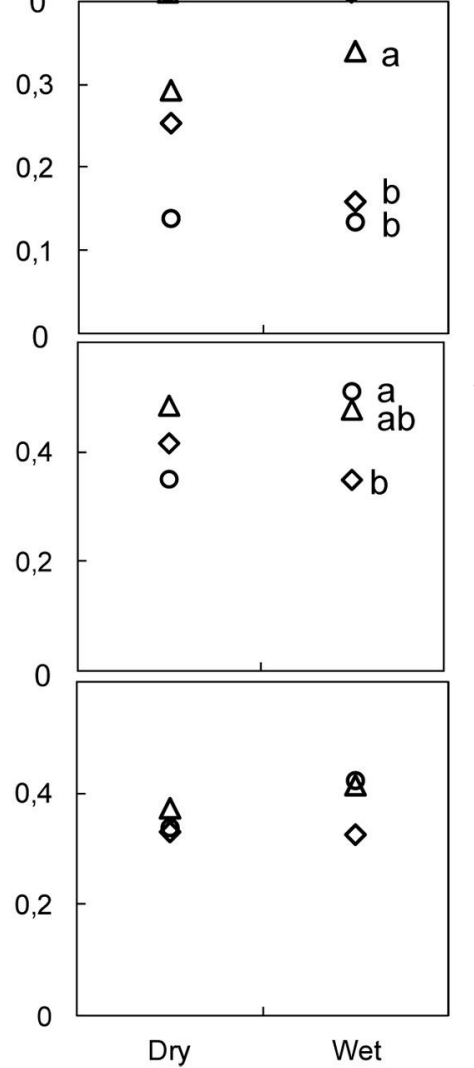

Fig. 3 - Community weighted mean (CWM), functional evenness, and functional dispersion in dry and wet locations.

Traits: N-fixing ability (binary), onset of flowering (semi-quantitative), and height and specific leaf area (SLA - quantitative).

Methods: modified-

Whittaker (MW, diamonds); Dengler (DE, triangles); point-intercept (PT, circles). Different letters indicate significant differences between methods after Bonferroni's test adjusted at $\mathrm{P}<0.017$ $(\mathrm{N} \geq 6)$. in the survey affects community weighted means, functional evenness, and functional divergence. All such parameters are required to achieve a reliable assessment of the functional structure and diversity of plant communities.

Although no differences among the three methods were found in the time needed for the survey, the observed differences in their efficiency in quantifying the species/traits abundance point out important advantages of the PT method in non-destructive fine-scale monitoring of plant functional diversity in semi-arid areas. Firstly, this method allowed the detection of as many species as the MW method and of a higher number than the DE method. It also provided a higher precision in cover estimates and, because of higher community evenness, more species/traits could be analyzed within the advocated $80 \%$ "dominance" threshold (species representing $80 \%$ of the relative cover of the community). Therefore, the PT method offers a cost-effec- tive way to reduce "sampling error", by reducing the subjectivity in species cover estimates and improving functional diversity estimates. Secondly, this method is less vulnerable to the operator's bias and thus likely more reproducible when used by different operators (Elzinga et al. 2001). It is worth to stress that we did not aim at testing the effect of different observers, e.g., through ring tests to assess the "observer error" (Giordani et al. 2009). Instead, we assumed a priori that the reproducibility of the PT method is higher (lower observer-bias) when used by experienced botanists familiar with the local flora.

The PT method has proven to be more efficient across contrasting environments (different precipitation regimes) and showed consistency even across different plant density or diversity. These features are critical for a precise and reproducible assessment of changes in functional diversity of plant community in response to environmental changes. In this study, the PT method outper- formed other methods commonly used for fine-scale monitoring of plant functional diversity in the understory of Holm-oak woodlands. Similarly, we hypothesized its superior performances also in vegetation surveys of semi-arid areas characterized by low tree density and/or dominated by grasslands and/or shrubland patches. However, further analyses are needed before extending our results to other ecosystems like boreal or temperate forests.

\section{Species quantification and richness}

With the PT and MW methods, a higher number of species was quantified than with the DE method, i.e., PT and MW performed better in species/traits quantification. This is a critical step in functional diversity assessments. Even though our study was not aimed at testing methods to assess species richness per se, we found that using the two areabased methods considered (MW and DE) a higher overall number of species was de- 
tected, as a consequence of the inclusion of an extra $1000-\mathrm{m}^{2}$ plot for the detection of "new" species presence. However, if species richness is an index of interest in the survey, the PT method could be easily complemented with a search for new species in a predefined surrounding area with little extra time.

\section{Precision of cover estimates}

The PT method adopted in this study provided plant cover estimates more precise than those obtained with the other methods tested. At the dry location, major differences were found for main genera and families Cover estimates by the PT method were shown to be particularly sensitive to plant architecture and leaf morphology of understory plants (Abrahamson et al. 2011). However, such method performed similarly or even better than others in monitoring groups of species with distinct morphology (e.g., Asteraceae), ensuring at the same time similar or higher precision in the assessment of cover by species group as well. At the wet location, precision differences concerned mainly individual species' estimates, either dominant or not, with a consistent advantage of the PT method in the case of varying plant density or diversity. In accordance with our results, other authors using the PT method in herbaceous communities, have reported a precision similar or higher than that obtained by cover visual estimates (Vittoz \& Guisan 2007). Precision in plant abundance quantification is an essential prerequisite of a reproducible method suitable to fine-scale monitoring of functional diversity of herbaceous communities, where changes in species abundance may be hard to detect (e.g. dense/rich communities).

\section{Evenness and quantification of less abundant species}

In the wet location analyzed, community evenness estimates obtained with the PT method were higher than those resulted from the application of the other methods, with small differences in relative cover from more to less abundant species. Likely, such differences were underlying the divergence of functional evenness estimates among the three methods considered. Community evenness plays an important role in ecosystem processes and multifunctionality (Hillebrand et al. 2008, Maestre et al. 2012a). Functional evenness reflects the distribution of traits in a community and thus the degree of niche space occupation by coexisting species (Mason et al. 2005). It often responds more rapidly to environmental changes than species richness and may have a rapid and strong impact on ecosystem functions (Chapin et al. 2000, Mouillot et al. 2011). Areabased methods implying visual cover estimates (MW and DE) tend to overestimate the dominant and more conspicuous species and underestimate those less abundant (Vittoz \& Guisan 2007), with accordingly lower evenness. This was the case at the wet location, where seven species attained $80 \%$ relative cover according to the MW method, while seventeen species were needed to achieve the same threshold with the PT method. It is important to take into account the role of less common species in functional diversity assessments. A threshold of $80 \%$ (in terms of species number or their cover) has been advocated as representative in the description of functional composition (Garnier et al. 2004, Pakeman \& Quested 2007). Such threshold is based on the assumption that dominant species are functionally more important because of their higher abundance, following the mass-ratio hypothesis (Grime 1998). Thus, since the adoption of the PT method included more species (and more functional traits) within the above threshold, it follows that PT performed better for purposes of assessing functional diversity. Moreover, the role of less common species in drought-prone ecosystems may be critical, both over the short- and the long-term. In dry-lands, inter-annual climatic fluctuations are high, forcing species to cope with extreme values of the environmental factors. Consequently, they often exhibit a dynamic turnover involving shifts in the abundance of response groups when a rainy year is followed by a severely dry one, especially in communities dominated by annual species (Aronson \& Shmida 1992, Adler \& Levine 2007, Elmendorf \& Harrison 2009). Therefore, in contrast to more mesic areas, less abundant species in dry-lands are likely to play a major role in the ecosystem resilience, as a consequence of their capability of exploiting outstanding environmental conditions, as proposed by the complementarity hypothesis (Grime 1998, Walker et al. 1999, Loreau 2000). This argument supports the relative importance of less abundant species and thus their inclusion in functional diversity assessments. In a study on grasslands by McIntyre \& Lavorel (2001), the range of different traits exhibited by forbs and smaller grasses contributed to a varying environmental response, in contrast to local dominant grasses. In our study, this seemed to be the case of $\mathrm{N}$-fixing species. Despite the fact that their relative cover did not exceed $3.0 \%$ and $17.6 \%$ at the dry and wet locations, respectively, they represented a highly relevant functional feature of drylands, usually characterized by soil $\mathrm{N}$ shortage (Sprent \& Gehlot 2010). Furthermore, dry-lands are highly susceptible to land degradation and desertification (Reynolds et al. 2007). These processes most likely depend on a critical threshold beyond which drastic alterations occur, preceded by more subtle functional changes in communities (Reynolds et al. 2007, Scheffer et al. 2001). It is therefore important to monitor such changes, as they represent early-warning indicators and allow a timely adoption of counteracting prevention activities.

\section{Cover estimates}

Absolute cover estimates were generally higher with the PT method than with either other methods, as previously reported in the literature (Abrahamson et al. 2011). This effect has been attributed to the error due to the diameter of the rod used in sampling, which should be as thin as possible (Elzinga et al. 2001). However, this is not a problem when the aim is to monitor changes through time and it should not affect the computation of functional metrics using the relative cover of species/traits.

\section{Conclusions}

In this study, we demonstrated that the PT, MW, and DE methods differed in terms of efficiency in the assessment of species/traits relative abundances, thus affecting estimates of functional diversity. The PT method had important advantages over the others with respect to fine-scale monitoring of plant functional diversity in the mainly grassy understory of Holm oak woodlands, and likely in semi-arid areas in general as well. The adoption of the PT method allowed the detection of as many species as the MW method and of more species than the DE method, with a higher precision of cover estimates both for groups of species and at the single-species level. Moreover, due to higher community evenness, it allowed the analysis of a greater number of species/traits within the advocated $80 \%$ "dominance" threshold. Precision of the estimates is a prerequisite of functional diversity surveys, in that they must include not only dominant species and traits, because of their larger contribution to ecosystem functionality, but also less common ones, given their decisive role in the resilience and function of semi-arid ecosystems, thereby integrating the mass ratio and complementarity hypotheses (Loreau 2000). The advantages of the PT method were proven across contrasting environmental conditions. In addition, it should be less biased than those based on visual estimation and thus more reproducible when used by different operators.

\section{Acknowledgements}

Authors' contributions: AN, ST, OC, and $\mathrm{CB}$ conceived of and designed the experiments, AN and ST performed the experiments, $\mathrm{AN}$ and $\mathrm{CB}$ analyzed the data, $\mathrm{AN}$, $\mathrm{PP}, \mathrm{OC}$, and $\mathrm{CB}$ wrote the manuscript. This research was funded through the FCT-MEC DesertWarning project (PTDC/AAC-CLI/10 4913/2008) and through SFRH/BPD/754 25/2010 and SFRH/BD/51407/2011 fellowships. 


\section{References}

Abrahamson IL, Nelson CR, Affleck DL (2011) Assessing the performance of sampling designs for measuring the abundance of understory plants. Ecological Applications 21 (2): 452-464. - doi: 10.1890/09-2296.1

Adler PB, Levine JM (2007). Contrasting relationships between precipitation and species richness in space and time. Oikos 116: 221-232. - doi: 10.1111/j.0030-1299.2007.15327.x

Aronson J, Shmida A (1992). Plant species diversity along a Mediterranean-desert gradient and its correlation with interannual rainfall fluctuations. Journal of Arid Environments 23: 235 247. [online] URL: http://bio.huji.ac.il/upload/ E083-CPlantspeciesdiversityalongaMediterranean.pdf

Atlas Digital do Ambiente (2011). Climate Atlas of Portugal. Agência Portuguesa do Ambiente (APA), Ministerio do Ambiente, Ordenamento do Territorio e Energia, Governo de Portugal, web site. [in Portuguese] [online] URL: http:// www.apambiente.pt/

Bernard-Verdier M, Navas ML, Vellend M, Violle C, Fayolle A, Garnier E (2012). Community assembly along a soil depth gradient: contrasting patterns of plant trait convergence and divergence in a Mediterranean rangeland. Journal of Ecology 100: 1422-1433. - doi: 10.1111/13652745.12003

Castro H (2008). Effects of land use change on plant composition and ecosystem functioning in an extensive agro-pastoral system: plant functional traits and ecosystem processes. $\mathrm{PhD}$ thesis, University of Coimbra, Portugal, pp. 144.

Chapin FS, Zavaleta ES, Eviner VT, Naylor RL, Vitousek PM, Reynolds HL, Hooper DU, Lavorel S, Sala OE, Hobbie SE, Mack MC, Díaz S (2000). Consequences of changing biodiversity. Nature 405: 234-242. - doi: 10.1038/35012241

Cornelissen JHC, Lavorel S, Garnier E, Díaz S, Buchmann N, Gurvich DE, Reich PB, ter Steege $\mathrm{H}$, Morgan HD, van der Heijden MGA, Pausas JG, Poorter H (2003). Handbook of protocols for standardized and easy measurement of plant functional traits worldwide. Australian Journal of Botany 51: 335-380. - doi: 10.1071/BT02124

De Bello F, Leps J, Sebastia MT (2005). Predictive value of plant traits to grazing along a climatic gradient in the Mediterranean. Journal of Applied Ecology 42: 824-833. - doi: 10.1111/j.136 5-2664.2005.01079.x

De las Heras MM, Saco PM, Willgoose GR, Tongway DJ (2011). Assessing landscape structure and pattern fragmentation in semiarid ecosystems using patch-size distributions. Ecological Applications 21: 2793-2805. - doi: 10.1890/ 10-2113.1

Dengler J (2009). A flexible multi-scale approach for standardized recording of plant species richness patterns. Ecological Indicators 9: 11691178. - doi: 10.1016/j.ecolind.2009.02.002

Díaz S, Lavorel S, de Bello F, Quétier F, Grigulis K, Robson TM (2007). Incorporating plant functional diversity effects in ecosystem service assessments. Proceedings of the National Academy of Sciences USA 104: 20684-20689. - doi: 10.10 73/pnas.0704716104

Elmendorf SC, Harrison SP (2009). Temporal variability and nestedness in California grassland species composition. Ecology 90 (6): 1492-1497. - doi: 10.1890/08-1677.1

Elzinga CL, Salzer DW, Willoughby JW (2001). Measuring and monitoring plant populations. Bureau of Land Management National Business Center, Denver, CO, USA, pp. 477.

Fischer LK, von der Lippe M, Kowarik I (2013). Urban grassland restoration: which plant traits make desired species successful colonizers? Applied Vegetation Science 16: 272-285. - doi: 10.1111/j.1654-109X.2012.01216.x

Floyd DA, Anderson JE (1987). A comparison of three methods for estimating plant cover. Journal of Ecology 75: 221-228. - doi: 10.2307/2260547 Franco JA (1971). Nova flora de Portugal (continente e Açores) [New flora of Portugal (mainland and Açores)]. Sociedade Astória Lda, Lisbon, Portugal, vol. 1-2, pp. 555+659.

Frenette-Dussault C, Shipley B, Léger J, Meziane D, Hingrat Y (2012). Functional structure of an arid steppe plant community reveals similarities with Grime's C-S-R theory. Journal of Vegetation Science 23 (2): 208-222. - doi: 10.1111/j.16 54-1103.2011.01350.x

Garnier E, Cortez J, Billès G, Navas ML, Roumet C, Debussche M, Laurent G, Blanchard A, Aubry D, Bellmann A, Neill C, Toussaint JP (2004). Plant functional markers capture ecosystem properties during secondary succession. Ecology 85: 2630-2637. - doi: 10.1890/03-0799 Gerhold P, Price JN, Pussa K, Kalamees R, Aher K, Kaasik A, Partel M (2013). Functional and phylogenetic community assembly linked to changes in species diversity in a long-term resource manipulation experiment. Journal of Vegetation Science 24: 843-864. - doi: 10.1111/jvs. 12052

Giordani P, Brunialti G, Benesperi R, Rizzi G, Frati L, Modenesi P (2009). Rapid biodiversity assessment in lichen diversity surveys: implications for quality assurance. Journal of Environmental Monitoring 11 (4): 730-735. - doi: 10.10 39/b818173j

Goodall DW (1953). Point quadrat methods for the analysis of vegetation - the treatment of data for tussock grasses. Australian Journal of Botany 1 (3): 457-461. - doi: 10.1071/BT9530457

Grime JP (1998). Benefits of plant diversity to ecosystems: immediate, filter and founder effects. Journal of Ecology 86: 902-910. - doi: 10.1046/j.1365-2745.1998.00306.x

Hillebrand H, Bennett DM, Cadotte MW (2008). Consequences of dominance: a review of evenness effects on local and regional ecosystem processes. Ecology 89: 1510-1520. - doi: 10.1890/ 07-1053.1

Kent M, Coker P (1992). Vegetation description and analysis - a practical approach. John Wiley \& Sons, Chichester, UK, pp. 363.

Laliberte E, Legendre P (2010). A distance-based framework for measuring functional diversity from multiple traits. Ecology 91: 299-305. - doi:
10.1890/08-2244.1

Laliberte E, Shipley B (2011). FD: measuring functional diversity from multiple traits, and other tools for functional ecology. $\mathrm{R}$ package version 10-11. [online] URL: http://cran.r-pro ject.org

Lavorel S, Grigulis K, McIntyre S, Garden D, Williams N, Dorrough J, Berman S, Quétier F, Thébault A, Bonis A (2008). Assessing functional diversity in the field - methodology matters! Functional Ecology 22: 134-147. - doi: 10.1111/ j.1365-2435.2007.01339.x

Lewontin R (1966). On the measurement or relative variability. Systematic Zoology 15: 141-142. - doi: 10.2307/2411632

Loreau M (2000). Biodiversity and ecosystem functioning: recent theoretical developments. Oikos 91: 3-17. - doi: 10.1034/j.1600-0706.20 00.910101.x

Maestre FT, Quero JL, Gotelli NJ, Escudero A, Ochoa V, Delgado-Baquerizo M, García-Gómez M, Bowker MA, Soliveres S, Escolar C, GarcíaPalacios P, Berdugo M, Valencia E, Gozalo B, Gallardo A, Aguilera L, Arredondo T, Blones J, Boeken B, Bran D, Conceicao A, Cabrera O, Chaieb M, Derak M, Eldridge D, Espinosa CI, Florentino A, Gaitán J, Gatica MG, Ghiloufi W, Gómez-González S, Gutiérrez JR, Hernández RM, Huang X, Huber-Sannwald E, Jankju M, Miriti M, Monerris J, Mau RL, Morici E, Naseri K, Ospina A, Polo V, Prina A, Pucheta E, Ramírez-Collantes DA, Romão R, Tighe M, Torres-Díaz C, Val J, Veiga JP, Wang D, Zaady E (2012a). Plant species richness and ecosystem multifunctionality in global drylands. Science 335: 214-218. - doi: 10.1126/science. 1215442 Maestre FT, Castillo-Monroy AP, Bowker MA, Ochoa-Hueso R (2012b). Species richness effects on ecosystem multifunctionality depend on evenness, composition and spatial pattern. Journal of Ecology 100: 317-330. - doi: 10.1111/j.13 65-2745.2011.01918. $\mathrm{x}$

Mason N, Mouillot D, Lee W, Wilson J (2005). Functional richness, functional evenness and functional divergence: the primary components of functional diversity. Oikos 111: 112-118. doi: 10.1111/j.0030-1299.2005.13886.x

McIntyre S, Lavorel S (2001). Livestock grazing in sub-tropical pastures: steps in the analysis of attribute response and plant functional types. Journal of Ecology 89: 209-226. - doi: 10.1046/ j.1365-2745.2001.00535.x

Mouillot D, Villéger S, Scherer-Lorenzen M, Mason NWH (2011). Functional structure of biological communities predicts ecosystem multifunctionality. PLoS ONE 6 (3): e17476. - doi: 10.13 71/journal.pone.0017476

Nicolau M (2002). Modeling and mapping the spatial distribution of precipitation. An application to Portugal mainland. $\mathrm{PhD}$ thesis, Universidade de Lisboa, Lisbon, Portugal.

Pakeman RJ, Quested HM (2007). Sampling plant functional traits: what proportion of the species need to be measured? Applied Vegetation Science 10: 93-8. - doi: 10.1111/j.1654-109X.2007. tb00507.x 
Pielou, EC (1975). Indices of diversity and evenness. In: "Ecological Diversity" (Pielou EC ed). John Wiley \& Sons, New York, pp. 5-18.

Porto M, Correia O, Beja P (2011). Long-term consequences of mechanical fuel management for the conservation of Mediterranean forest herb communities. Biodiversity Conservation 20 2669-2691. - doi: 10.1007/s10531-011-0098-9

Prieur-Richard AH, Lavorel S, Dos Santos A, Grigulis K (2002). Mechanisms of resistance of Mediterranean annual communities to invasion by Conyza bonariensis: effects of native functional composition. Oikos 99: 338-346. - doi 10.1034/j.1600-0706.2002.990215.x

R Core Team (2013). R: A language and environment for statistical computing R Foundation for Statistical Computing, Vienna, Austria. [online] URL: http://www.R-project.org/

Reynolds JF, Stafford Smith DM, Lambin EF, Turner II BL, Mortimore M, Batterbury SP, Downing TE, Dowlatabadi H, Fernandéz RJ, Herrick JE, Huber-Sannwald E, Jiang H, Leemans R, Lynam T, Maestre FT, Ayarza M, Walker B (2007). Global desertification: building a science for dryland development. Science 316: 847-851. - doi: 10.1126/science.1131634 Scheffer M, Carpenter S, Foley JA, Folke C, Walker B (2001). Catastrophic shifts in ecosystems. Nature 413: 591-596. - doi: 10.1038/35098000

Schleuter D, Daufresne M, Massol F, Argillier C (2010). A user's guide to functional diversity indices. Ecological Monographs 80 (3): 469-484. - doi: 10.1890/08-2225.1

Sprent JI, Gehlot HS (2010). Nodulated legumes in arid and semi-arid environments: are they important? Plant Ecology and Diversity 3 (3): 211 219. - doi: 10.1080/17550874.2010.538740

Stohlgren TJ, Falkner MB, Schell LD (1995). A modified-Whittaker nested vegetation sampling method. Plant Ecology 117 (2): 113-121. - doi: 10.1007/BF00045503

Talavera S, Aedo C, Castroviejo S, Romero Zarco C, Sáez L, Salgueiro FJ, Velayos M (1999). Flora iberica. Plantas vasculares de la Península Ibérica e Islas Baleares [Flora iberica. Vascular plants of the Iberian Peninsula and Balearic Islands]. Real Jardín Botánico, CSIC, Madrid, Spain, pp. 34. [online] URL: http://www.floraiberica.es/eng/ [in Spanish]

Tilman D, Knops J, Wedin D, Reich P, Ritchie M, Siemann E (1997). The influence of functional diversity and composition on ecosystem processes. Science 277: 1300-1302. - doi: 10.1126/ science. 277.5330 .1300

Verrill S, Johnson RA (2007). Confidence bounds and hypothesis tests for normal distribution coefficients of variation. Communications in Statistics, Theory and Methods 36: 2187-2206. - doi: 10.1080/03610920701215126

Villéger S, Mason N, Mouillot D (2008). New multidimensional functional diversity indices for a multifaceted framework in functional ecology. Ecology 89: 2290-2301. - doi: 10.1890/07-120 6.1
Vittoz P, Guisan A (2007). How reliable is the monitoring of permanent vegetation plots? A test with multiple observers. Journal of Vegetation Science 18: 413-422. - doi: 10.1111/j.1654-110 3.2007.tb02553.x

Walker BH, Kinzig A, Langridge J (1999). Plant attribute diversity, resilience, and ecosystem function: the nature and significance of dominant and minor species. Ecosystems 2: 95-113. doi: $10.1007 /$ s 100219900062

\section{Supplementary Material}

\section{Appendix 1}

Tab. S1. List of species recorded and trait category or value trait assigned. Nomenclature follows that of the Flora Iberica (Talavera et al. 1999).

Fig. S1. Community-weighted mean (CWM - Garnier et al. 2004), functional evenness (Villéger et al. 2008), and functional dispersion (Laliberte \& Legendre 2010) for graminoid growth form and anemochorous dispersal mode (binary traits), life cycle, and flowering duration (semi-quantitative traits), in dry and wet locations.

Link: Nunes_1261@supp1001.pdf 